\title{
Effectiveness and Safety of EGFR-TKI Rechallenge Treatment in Elderly Patients with Advanced Non-Small-Cell Lung Cancer Harboring Drug-Sensitive EGFR Mutations
}

\author{
Yutaka Yamada $1, *,+\left(\mathbb{D}\right.$, Hisao Imai ${ }^{2,3,+}+\mathbb{D}$, Tomohide Sugiyama ${ }^{4,+}$, Hiroyuki Minemura ${ }^{5,+} \mathbb{C}$, Kenya Kanazawa ${ }^{5,6,+}$, \\ Takashi Kasai ${ }^{4,+}$, Koichi Minato ${ }^{3, \dagger}$, Kyoichi Kaira ${ }^{2,+}+$ and Takayuki Kaburagi ${ }^{1,+}$ \\ 1 Department of Respiratory Medicine, Ibaraki Prefectural Central Hospital, Kasama 309-1793, Ibaraki, Japan; \\ t-kaburagi@chubyoin.pref.ibaraki.jp \\ 2 Department of Respiratory Medicine, Comprehensive Cancer Center, International Medical Center, \\ Saitama University Hospital, Hidaka 350-1298, Saitama, Japan; m06701014@gunma-u.ac.jp (H.I.); \\ kkaira1970@yahoo.co.jp (K.K.) \\ 3 Division of Respiratory Medicine, Gunma Prefectural Cancer Center, Ota 373-8550, Gunma, Japan; \\ kminato@gunma-cc.jp \\ 4 Division of Thoracic Oncology, Tochigi Cancer Center, Utsunomiya 320-0834, Tochigi, Japan; \\ tomsugiy@tochigi-cc.jp (T.S.); takasai@tochigi-cc.jp (T.K.) \\ 5 Department of Pulmonary Medicine, Fukushima Medical University, Fukushima 960-1295, Japan; \\ hiromine1129@gmail.com (H.M.); k-kenya@fmu.ac.jp (K.K.) \\ 6 Clinical Oncology Center, Fukushima Medical University Hospital, Fukushima 960-1295, Japan \\ check for \\ updates \\ * Correspondence: gyyamada@muf.biglobe.jp or y-yamada@chubyoin.pref.ibaraki.jp; Tel.: +81-296-77-1121 \\ † Gunma-Ibaraki-Fukushima-Tochigi (GIFT) Group.
}

Citation: Yamada, Y.; Imai, H.; Sugiyama, T.; Minemura, H.; Kanazawa, K.; Kasai, T.; Minato, K.; Kaira, K.; Kaburagi, T. Effectiveness and Safety of EGFR-TKI Rechallenge Treatment in Elderly Patients with Advanced Non-Small-Cell Lung Cancer Harboring Drug-Sensitive EGFR Mutations. Medicina 2021, 57, 929. https://doi.org/10.3390/ medicina57090929

Academic Editor: Paul Zarogoulidis

Received: 29 July 2021

Accepted: 1 September 2021

Published: 3 September 2021

Publisher's Note: MDPI stays neutral with regard to jurisdictional claims in published maps and institutional affiliations.

Copyright: (c) 2021 by the authors. Licensee MDPI, Basel, Switzerland. This article is an open access article distributed under the terms and conditions of the Creative Commons Attribution (CC BY) license (https:/ / creativecommons.org/licenses/by/ $4.0 /)$.
Abstract: Background and Objectives: Epidermal growth factor receptor-tyrosine kinase inhibitors (EGFR-TKIs) are effective first-line chemotherapeutic agents for patients with advanced non-smallcell lung cancer (NSCLC) harboring drug-sensitive EGFR mutations. However, the effectiveness of EGFR-TKI rechallenge after first-line EGFR-TKI treatment is not sufficient in elderly patients (over 75 years of age) harboring drug-sensitive EGFR mutations. Therefore, we investigated the effectiveness and safety of EGFR-TKI rechallenge after first-line EGFR-TKI treatment in elderly patients with advanced NSCLC harboring drug-sensitive EGFR mutations. Materials and Methods: Between April 2008 and December 2015, we analyzed 78 elderly patients with advanced NSCLC harboring drug-sensitive EGFR mutations with first-line EGFR-TKI treatment at four Japanese institutions. We retrospectively evaluated the clinical effectiveness and safety profiles of EGFR-TKI rechallenge after first-line EGFR-TKI treatment in elderly patients with advanced NSCLC harboring drug-sensitive EGFR mutations (exon 19 deletion/exon 21 L858R mutation). Results: Twenty-two patients in the cohort were rechallenged with EGFR-TKI. The median age was 79.5 years (range 75-87 years). Despite the fact that it was a retrospective analysis, even with EGFR-TKI rechallenge treatment the response rate was $23 \%$, progression-free survival was 5.3 months, and overall survival was 14.4 months. Common adverse events included rash acneiform, paronychia, diarrhea, and anorexia. There were no treatment-related deaths. Due to the occurrence of adverse events of grade 2 or more, dose reduction was performed in 15 (68.2\%) of 22 cases. Conclusions: EGFR-TKI rechallenge treatment after first-line EGFR-TKI treatment in elderly patients with advanced NSCLC harboring drug-sensitive EGFR mutations was one of the limited, safe and effective treatment options for elderly EGFR-positive lung cancer patients.

Keywords: epidermal growth factor receptor; advanced non-small-cell lung cancer; elderly patients; re-administration; tyrosine kinase inhibitor; EGFR-TKI; EGFR mutations; secondary chemotherapy

\section{Introduction}

Population aging and progress of cancer treatment increased the number of elderly lung cancer patients [1]. More than $50 \%$ of lung cancer patients are diagnosed at over 
65 years old. This is the lower limit to define the 'elderly' in epidemiological studies [2]. In addition, $85 \%$ of adult lung cancer consists of non-small cell lung cancer (NSCLC) [3]. As first-line treatment for patients with advanced NSCLC harboring drug-sensitive EGFR mutations, previous clinical trials showed the effectiveness of epidermal growth factor receptortyrosine kinase inhibitors (EGFR-TKIs) such as gefitinib, erlotinib and afatinib [4-9]. Furthermore, in elderly patients with advanced NSCLC harboring EGFR mutations, gefitinib and erlotinib as a first-line treatment provided high response rate (RR) and long-term survival [10-15].

In EGFR gene mutation-positive patients, there are no guidelines for determining the order of administration of EGFR-TKI monotherapy and cytotoxic anticancer agents. However, for patients with EGFR mutation-positive cancer, it is recommended not to miss treatment by EGFR-TKI single agent. The main toxicities associated with EGFR-TKI are diarrhea, skin rash, paronychia, and hepatic dysfunction. Although the frequency and severity of toxicity are different for each drug, it has been suggested that drug suspension and dose reduction enable long-term treatment continuation $[6,7,10,16-18]$.

For patients treated with single agent gefitinib or erlotinib as the first-line treatment, if a biopsy is positive for the EGFR T790M mutation, osimertinib can be given as a single agent for the second-line treatment. Nevertheless, T790M negative cases after re-biopsy are currently being treated according to the first-line treatment of NSCLC without driver mutation (e.g., EGFR, ALK (anaplastic lymphoma kinase), ROS1).

In clinical practice, administration of osimertinib was previously required to obtain T790M-positive results by biopsy. However, in the elderly, it may be difficult to re-biopsy. Therefore, it is common practice for EGFR-positive elderly patients to receive cytotoxic chemotherapy as second-line treatment, or to re-administer a different EGFR-TKI as a subsequent treatment.

The significance of EGFR-TKI re-administration in patients who relapsed after firstline EGFR-TKI treatment has been previously reported [18], but there have been no reports specifically on the elderly. To explore this clinical question, we conducted a retrospective study of the effectiveness, safety, and proportion of EGFR-TKI rechallenge treatment after first-line EGFR-TKI received in elderly patients (over 75 years of age) with advanced NSCLC harboring EGFR mutations.

This study was conducted additionally to a previous study by Imai et al., "Efficacy and safety of cytotoxic drug chemotherapy after first-line EGFR-TKI treatment in elderly patients with non-small-cell lung cancer harboring sensitive EGFR mutations" [19].

\section{Materials and Methods}

\subsection{Patients}

This study included 78 elderly patients with advanced NSCLC harboring drugsensitive EGFR mutations who were treated with EGFR-TKI as first-line treatment at four Japanese institutions between April 2008 and December 2015. The histological diagnosis and staging of NSCLC were based on the classification of the World Health Organization and the system of TNM staging, respectively [20]. Eligibility criteria were histologically or cytologically confirmed NSCLC, unresectable stage III/IV disease, and EGFR mutation (exon 18 G719X, exon 19 deletion or exon 21 L858R mutation). All patients were untreated with EGFR-TKIs and received first-line gefitinib $(250 \mathrm{mg} /$ day $)$ or erlotinib $(150 \mathrm{mg} /$ day $)$ and were then subsequently treated with other EGFR-TKIs (gefitinib, erlotinib, afatinib, or osimertinib). Treatments after the second-line treatment were determined by the treating physician. This continued until disease progression, intolerable toxicity, or withdrawal of treatment consent. To clarify EGFR-TKI rechallenge treatment performed in elderly patients with advanced EGFR mutation-positive advanced NSCLC, we collected cases in which the first-line treatment was gefitinib or erlotinib monotherapy, and finally EGFR-TKI rechallenge was performed.

A clinical chart search for eligible cases was conducted at each hospital. Records for baseline characteristics, chemotherapy regimens and responses to every EGFR-TKI 
treatment were also collected. This study was approved by an institutional review board of each institution.

\subsection{EGFR Mutation Analysis}

EGFR mutations were analyzed with allele specific real-time polymerase chain reaction (PCR) using biopsy or cytology specimens in each institution. The method for extracting genomic DNA is as previously described [21,22].

\subsection{Response Evaluation}

The best overall response and maximum tumor contraction were recorded as tumor responses. Tumor responses were classified as complete (CR), partial (PR), stable disease $(\mathrm{SD})$, progressive disease (PD), or not evaluable (NE), according to the response evaluation criteria in solid tumors (RECIST, version 1.1) [23].

\subsection{Statistical Analysis}

Fisher's exact test, the Chi-squared test and the Mann-Whitney U test were used to compare patient characteristics. The Kaplan-Meier method was used to estimate progression-free survival (PFS) and overall survival (OS). Adverse events of EGFR-TKI rechallenge were evaluated by the Common Terminology Criteria for Adverse Events (CTCAE), version 4.0. All statistical analyses were performed using SAS, version 9.4 (SAS Institute, Cary, NC, USA).

\section{Results}

\subsection{Patient Selection and Characteristics}

Figure 1 summarizes the number of patient selections and evaluation data at each time point. 78 qualified elderly patients with advanced NSCLC received first-line treatment with EGFR-TKIs. After failure of first-line EGFR-TKI treatment, patients were allowed subsequent treatment due to their own consensus, including continuation of EGFR-TKI treatment. Among these, 44 (54.3\%) received second-line chemotherapy, and 14 out of these 44 patients received rechallenge with EGFR-TKIs. Eight of the 14 patients who received second-line chemotherapy subsequently received EGFR-TKIs as third-line treatment. Consequently, a total of 22 patients were included in the EGFR-TKI rechallenge analysis.

Table 1 shows the characteristics of patients treated with EGFR-TKI rechallenge treatment. After starting first-line EGFR-TKI treatment, median PFS was 5.3 months and median OS was 14.4 months. The median follow-up was 14.6 months (range 3.2-31.2 months; Figure 2). Most of the subjects surveyed ( $82 \%$ ) had received administration of erlotinib after initial gefitinib treatment. In one case, gefitinib was re-administered after initial gefitinib treatment, and in another case erlotinib was re-administered after initial erlotinib treatment. However, in these two cases, a cytotoxic drug chemotherapy regimen was administered during EGFR-TKI rechallenge, not beyond PD. 


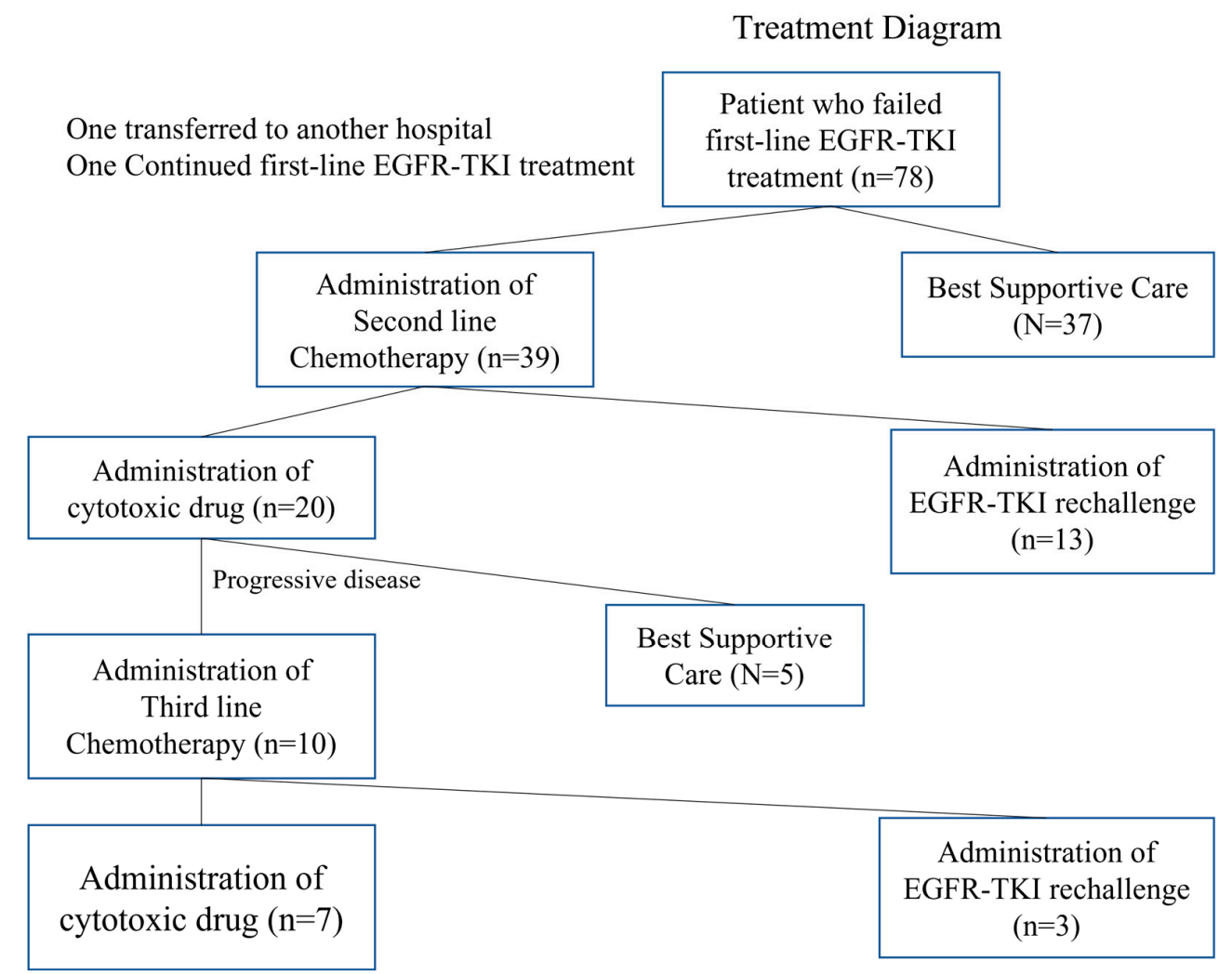

Figure 1. Study flow chart and patient treatment.

Table 1. Patients characteristics at initiation of EGFR-TKI rechallenge.

\begin{tabular}{ccc}
\hline Characteristics & Number of Patients & (\%) \\
Sex & 7 & 32 \\
Male & 15 & 68 \\
Female & $79.5(75-87)$ & \\
Age (years), median (range) & 7 & 32 \\
Performance status & 11 & 50 \\
0 & 4 & 18 \\
1 & 0 & 0 \\
2 & 0 & 0 \\
3 & & 4 \\
4 & 1 & 92 \\
Clinical Stage at diagnosis & 20 & 4 \\
IIIB & 1 & 100 \\
IV & & 0 \\
Postoperative recurrence & 22 & 28 \\
Histology & 0 & 68 \\
Adenocarcinoma & & 4 \\
Other otherwise specified & 6 & 45 \\
Curreng history & 15 & \\
Ner former & 1 & \\
Unknown & 10 & \\
EGFR mutation & & \\
Exon 19 deletion & & \\
\hline
\end{tabular}


Table 1. Cont.

\begin{tabular}{ccc}
\hline Characteristics & Number of Patients & (\%) \\
\hline Exon 21 L858R & 11 & 50 \\
Exon 18 G719X & 1 & 4 \\
First-line EGFR-TKI & & \\
Gefitinib & 19 & 86 \\
Erlotinib & 3 & 14 \\
Afatinib & 0 & 0 \\
Rechallenge EGFR-TKI & & 4 \\
Gefitinib $\rightarrow$ Gefitinib & 1 & 82 \\
Gefitinib $\rightarrow$ Erlotinib & 18 & 4 \\
Erlotinib $\rightarrow$ Erlotinib & 1 & 9 \\
Erlotinib $\rightarrow$ Gefitinib & 2 & 59 \\
2 & & 22 \\
3 & 13 & 18 \\
4 & 5 & 14 \\
Administration line of rechallenge EGFR-TKI & 4 & 4 \\
T790M mutation & 3 & 72 \\
Positive & 1 & \\
Unknotive & 18 & \\
\hline Median follow-up period [months] (range) & $14.6(3.2-31.2)$ &
\end{tabular}

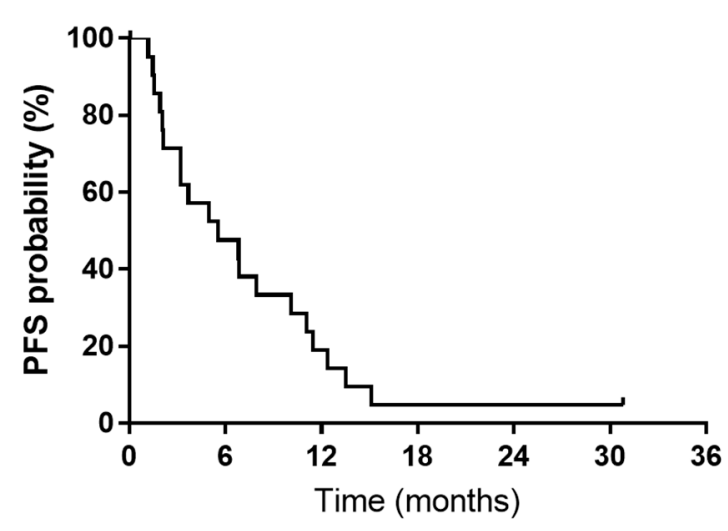

(a) Progression-free survival

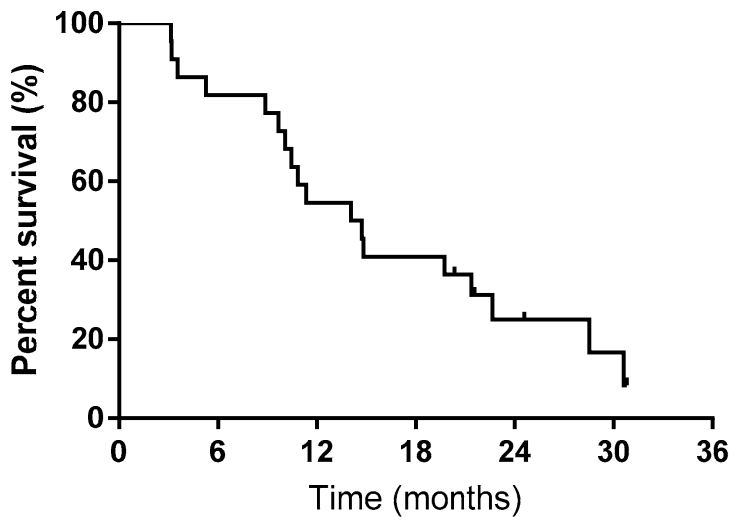

(b) Overall survival

Figure 2. Progression-free survival and overall survival in patients treated with EGFR-TKI rechallenge. (a) Kaplan-Meier plots showing progression-free survival (PFS). Median PFS 5.5 months. (b) Kaplan-Meier plots showing overall survival (OS). The median OS is 14.4 months.

\subsection{Treatment Efficacy}

Table 2 shows the objective tumor response to the first-line EGFR-TKI and the rechallenge after the first-line EGFR-TKI. None of the patients showed CR on EGFR-TKI rechallenge treatment, but 5 had PR, 12 had SD, and 4 had PD. Therefore, the overall RR was $23.0 \%$ and disease control rate was $77.0 \%$. 
Table 2. Response to first-line EGFR-TKI and rechallenge EGFR-TKI in patients with EGFR-mutated non-small-cell lung cancer and treatment delivery.

\begin{tabular}{|c|c|c|}
\hline & \multicolumn{2}{|c|}{ Number of Patients (\%) } \\
\hline & Primary EGFR-TKI & Rechallenge EGFR-TKI \\
\hline Complete response & $0(0)$ & $0(0)$ \\
\hline Partial response & $17(77)$ & $5(23)$ \\
\hline Stable disease & $1(4)$ & $12(54)$ \\
\hline Progressive disease & $4(19)$ & $4(19)$ \\
\hline Not evaluable & $0(0)$ & $1(4)$ \\
\hline Response rate (\%) & 77 & 23 \\
\hline Disease control rate ${ }^{\mathrm{a}}(\%)$ & 81 & 77 \\
\hline \multicolumn{3}{|l|}{$\begin{array}{c}\text { Dose reduction or alternative } \\
\text { day administration }\end{array}$} \\
\hline Yes $/$ No & $10 / 12$ & $15 / 7$ \\
\hline \multicolumn{3}{|c|}{$\begin{array}{l}\text { a The disease control rate is calculated as the number of patients with complete, partial, and stable disease divided } \\
\text { by the total study population. }\end{array}$} \\
\hline \multicolumn{3}{|c|}{$\begin{array}{l}\text { Table } 3 \text { shows the types of second-line chemotherapy regimen. The RR and disease } \\
\text { control rates (DCC) by EGFR mutations were } 20 \% \text { and } 90 \% \text { for exon } 19 \text { del, respectively, } \\
\text { and } 18.1 \% \text { and } 63.6 \% \text { for exon } 21 \text { L } 858 R \text {, respectively. Furthermore, when the cohort was } \\
\text { divided into those over or under } 80 \text { years of age, the RR and DCC rates were } 27.3 \% \text { and } \\
90.9 \% \text {, respectively, for those under } 80 \text { years of age, and } 18.2 \% \text { and } 63.6 \% \text {, respectively, for } \\
\text { those over } 80 \text { years of age. Ten patients received EGFR-TKI re-rechallenge regimens. Seven } \\
\text { of these cases were first- or second-generation EGFR-TKI re-rechallenge cases. Only two } \\
\text { patients were treated with immune checkpoint inhibitor after EGFR-TKI rechallenge. In the } \\
\text { case of PD after EGFR-TKI rechallenge of first- and second-generation EGFR-TKI, re-biopsy } \\
\text { was performed in four of } 22 \text { cases, and three of these were T790M-positive. Osimertinib } \\
\text { was subsequently administered as treatment in these three cases. }\end{array}$} \\
\hline
\end{tabular}

Table 3. Types of chemotherapy regimen between primary EGFR-TKI treatment and subsequent treatment.

\begin{tabular}{ccc}
\hline Regimen & \multicolumn{2}{c}{ Number of Patients } \\
\hline & $\begin{array}{c}\text { Therapies before EGFR-TKI } \\
\text { Rechallenge }\end{array}$ & $\begin{array}{c}\text { Therapies after Failure of EGFR-TKI } \\
\text { Rechallenge }\end{array}$ \\
\hline DTX & 5 & 0 \\
PEM & 3 & 7 \\
S-1 & 3 & 1 \\
CDDP-based combination chemotherapy & 0 & 0 \\
CBDCA-based combination & 2 & 0 \\
chemotherapy & 0 & 2 \\
Immune check point inhibitor & - & 7 \\
EGFR-TKI rechallenge (Gefitinib, \\
erlotinib, or afatinib) \\
Osimertinib * & - & 3 \\
Best supportive care & - & 9
\end{tabular}

EGFR-TKI, epiderDTX, docetaxel; PEM, pemetrexed; CDDP, cisplatin; CBDCA, carboplatin. * Osimertinib was administered to three T790M-positive patients on re-biopsy after rechallenge of first- and second-generation EGFR-TKIs.

\subsection{Survival Analysis}

PFS after rechallenge with EGFR-TKI was shorter than after first-line treatment of EGFR-TKI (log-rank, $p<0.05$ ). PFS during first-, second- and third-line treatment, and PFS after second-line, in the overall population are shown in Figure 3. 


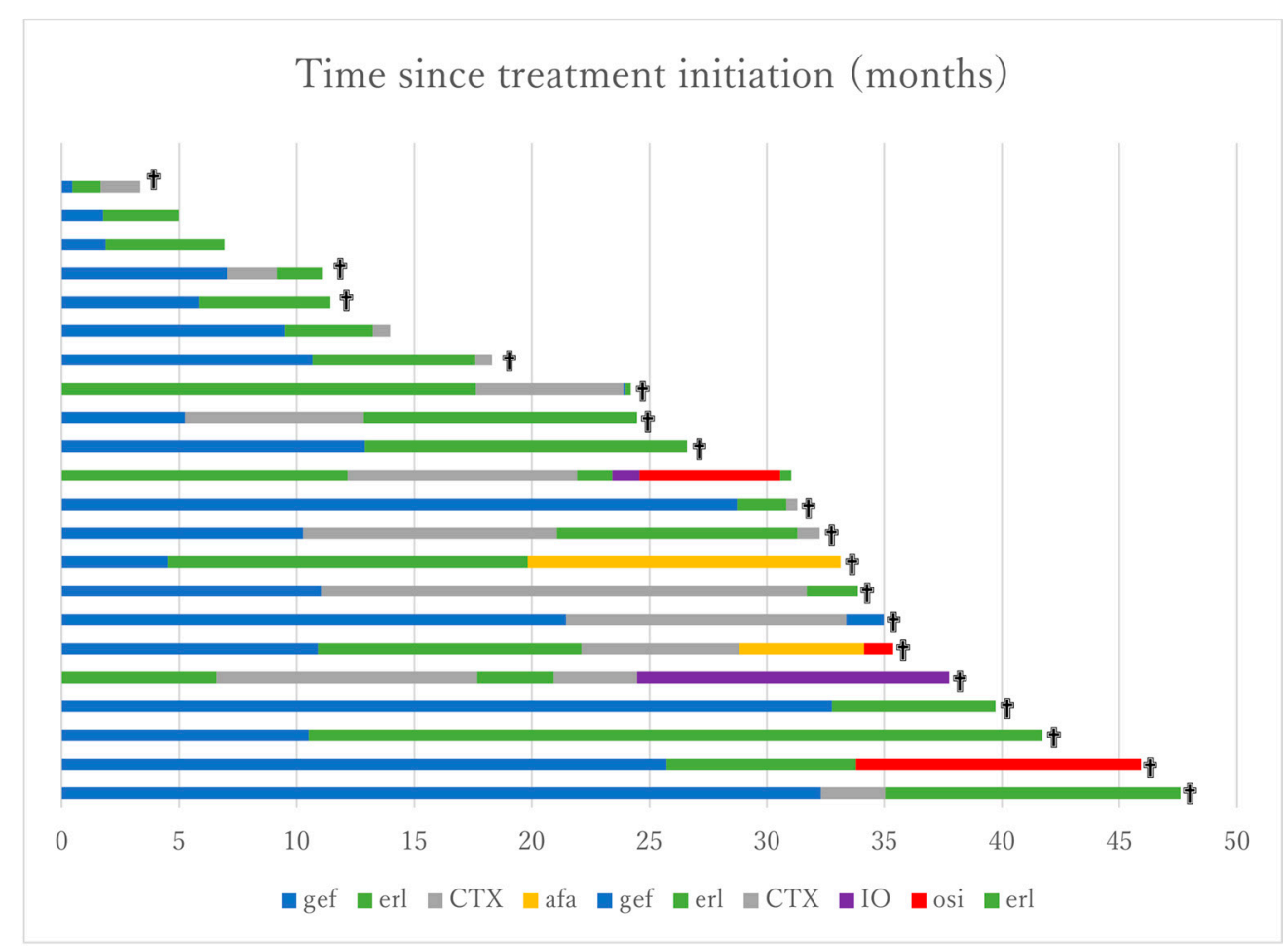

gef, gefitinib; erl, erlotinib; afa, Afatinib; osi, Osimertinib; CTX, chemotherapy; IO, immune checkpoint inhibitor; $¥$, Death case

Figure 3. Swimmer plots of 22 patients who received EGFR-TKI rechallenge treatment. Individual swimmer plots display duration of treatment methods.

\subsection{Toxicity and Adverse Events}

The toxicity of the EGFR-TKI rechallenge was evaluated in all patients, and the main adverse events during EGFR-TKI rechallenge are summarized in Table 4. Common adverse events were rash acneiform (total 14/22, 63.63\%; Grade 1, seven cases (31.81\%); Grade 2, seven cases $(31.81 \%)$ ), paronychia (total 8/22, 36.36\%; Grade 2, eight cases); diarrhea (total 9/22, 40.9\%; Grade 1, four cases (18.18\%); Grade 2, two cases (9.09\%); Grade 3, one case $(4.54 \%)$ ); and anorexia (total 5/22, 22.72\%; Grade 1, four cases )18.18\%); Grade 2, one case $(4.54 \%))$. There were no CTCAE Ver4.0 Grade 4 or higher adverse events in the 22 cases. Grade 3 adverse events were diarrhea $(n=1)$ and infection $(n=1)$. The total number of adverse events was 22 (Grade 1, 12 cases (54.5\%); Grade 2, eight cases (36.4\%): Grade 3, two cases $(9.09 \%)$ ). Furthermore, Grade 1 Anemia was observed in only three cases $(1.4 \%)$. The increase in AST / ALT was four cases (18.2\%) in Grade 1, and one case $(4.5 \%)$ in Grade 2, respectively.

Table 4. Adverse events associated with EGFR-TKI rechallenge in elderly patients with epidermal growth factor receptormutated non-small cell lung cancer.

\begin{tabular}{|c|c|c|c|c|c|c|}
\hline \multicolumn{7}{|c|}{ NCI-CTCAE Grade (Ver 4.0) } \\
\hline & 1 & 2 & 3 & 4 & 5 & $\geq 3(\%)$ \\
\hline \multicolumn{7}{|c|}{ Nonhematologic adverse events } \\
\hline Fatigue & 2 & 0 & 0 & - & - & $0(0)$ \\
\hline Paronychia & 0 & 8 & 0 & - & - & $0(0)$ \\
\hline Pruritus & 2 & 0 & 0 & - & - & $0(0)$ \\
\hline Rash acneiform & 7 & 7 & 0 & 0 & 0 & $0(0)$ \\
\hline Dyspnea & 3 & 0 & 0 & 0 & 0 & $0(0)$ \\
\hline
\end{tabular}


Table 4. Cont.

\begin{tabular}{|c|c|c|c|c|c|c|}
\hline \multicolumn{7}{|c|}{ NCI-CTCAE Grade (Ver 4.0) } \\
\hline & 1 & 2 & 3 & 4 & 5 & $\geq 3(\%)$ \\
\hline Anorexia & 4 & 1 & 0 & 0 & 0 & $0(0)$ \\
\hline Diarrhea & 4 & 2 & 1 & 0 & 0 & $1(4.5)$ \\
\hline Mucositis & 1 & 3 & 0 & 0 & 0 & $0(0)$ \\
\hline Nausea & 2 & 0 & 0 & 0 & 0 & $0(0)$ \\
\hline Pain & 1 & 0 & 0 & - & - & $0(0)$ \\
\hline Infection & 0 & 0 & 1 & 0 & 0 & $1(4.5)$ \\
\hline Pneumonitis & 0 & 0 & 0 & 0 & 0 & $0(0)$ \\
\hline Thromboembolic event & 0 & 1 & 0 & 0 & 0 & $0(0)$ \\
\hline \multicolumn{7}{|c|}{ Hematologic or laboratory adverse events } \\
\hline Anemia & 3 & 0 & 0 & 0 & 0 & $0(0)$ \\
\hline ALT increased & 4 & 1 & 0 & 0 & - & $0(0)$ \\
\hline AST increased & 4 & 1 & 0 & 0 & - & $0(0)$ \\
\hline
\end{tabular}

AST, aspartate aminotransferase; ALT, alanine aminotransferase.

\subsection{Dose Change of EGFR-TKI}

Due to the occurrence of adverse events of grade 2 or more, dose reduction was performed at $15(68.2 \%)$ of 22 cases. In 8 cases $(53.3 \%)$ of these 15 cases, there were further dose changes such as dose reduction or dose increase. In total, six cases $(40.0 \%)$ received second-line dose reduction. Furthermore, of the above 15 cases, four (26.3\%) responded to the increase in dose.

\subsection{Relationship with Body Surface Area}

The median body surface area (BSA) was $1.38 \mathrm{~m}^{2}$, and the average value was $1.44 \mathrm{~m}^{2}$. All cohorts showed very weak negative correlation $(R=-0.35)$. When the cohort was divided into those with BSA greater or less than $1.4 \mathrm{~m}^{2}$, there was no correlation below $1.4 \mathrm{~m}^{2}(\mathrm{R}=0.02)$ and there was a very weak negative correlation above $1.4 \mathrm{~m}^{2}(\mathrm{R}=-0.34)$ (Figure 4). The median PFS was 9.8 months in the low BSA group. In contrast, the median PFS was 3.5 months in the large BSA group, and median OS was 14.7 months in the low BSA group and 12.7 months in the large BSA group, respectively (Figure 5).

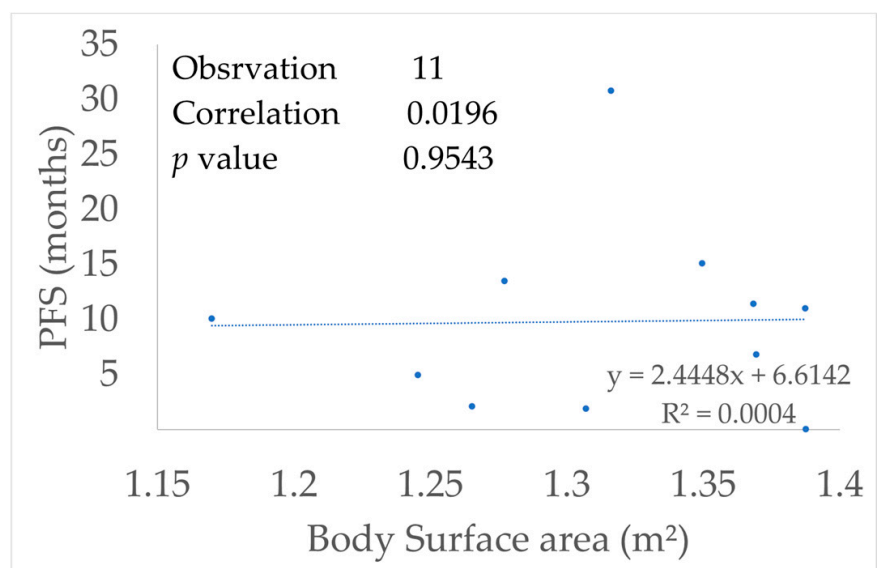

(a) Lower body surface area

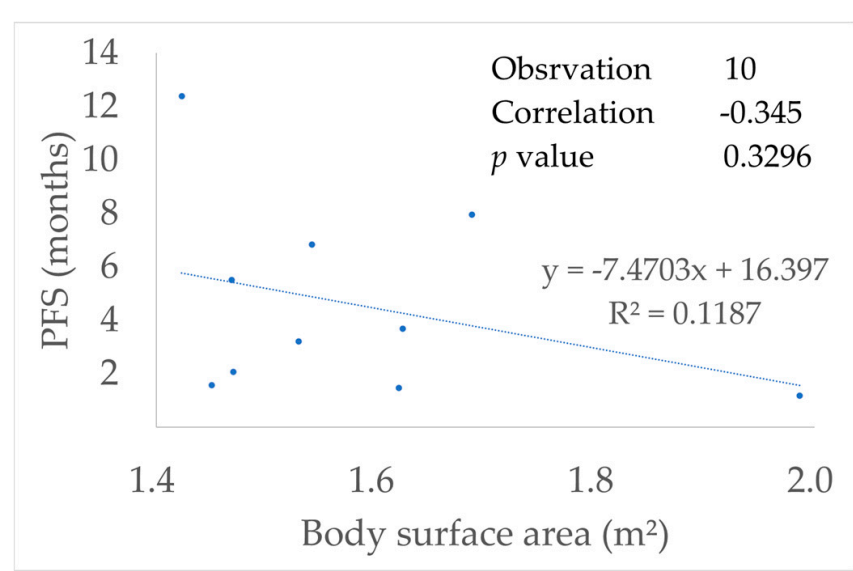

(b) Higher

Figure 4. Correlation between body surface area and progression-free survival (PFS). 


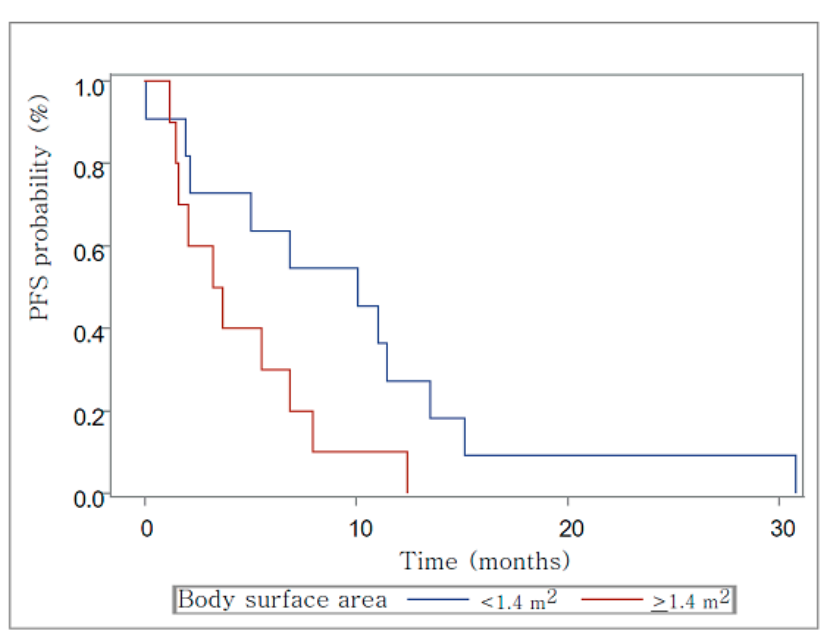

(a) Progression-free survival

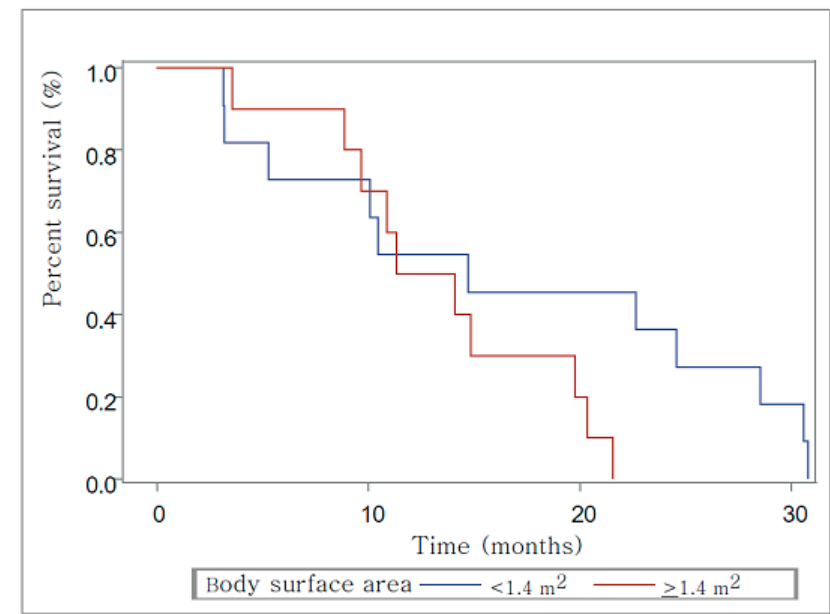

(b) overall survival

Figure 5. Progression-free survival (PFS) and overall survival (OS) of body surface area.

\subsection{Figures, Tables and Schemes}

EGFR-TKI, epidermal growth factor receptor-tyrosine kinase inhibitor.

Most Performance status at the start of treatment was 0-1. Most of the subjects surveyed $(82 \%)$ had administration of erlotinib after initial gefitinib treatment.

None of the patients showed CR on EGFR-TKI rechallenge treatment. Therefore, the overall RR was $23.0 \%$ and disease control rate was $77.0 \%$.

The BSC was the most selected after failure of EGFR-TKI rechallenge, and there were many cases of pemetrexed and re-rechallenge.

The table above lists all adverse events. There were no Grade 4 or higher adverse events in the 22 cases.

Common adverse events included rash acneiform, paronychia, diarrhea, and anorexia.

When the cohort was divided into those with BSA greater or less than $1.4 \mathrm{~m}^{2}$, there was no correlation below $1.4 \mathrm{~m} 2(\mathrm{R}=0.02)$ and there was a very weak negative correlation above $1.4 \mathrm{~m}^{2}(\mathrm{R}=-0.34)$.

The median PFS was 9.8 months in the low BSA group. In contrast, the median PFS was 3.5 months in the large BSA group, and median OS was 14.7 months in the low BSA group and 12.7 months in the large BSA group, respectively.

\section{Discussion}

In this study, about $28.2 \%$ of the elderly patients with NSCLC harboring drug-sensitive EGFR mutations underwent EGFR-TKI rechallenge after first-line EGFR-TKI treatment. Our study suggests that EGFR-TKI rechallenge treatment in elderly patients is safe and effective, and adverse events were tolerable.

Research such as LUX-LUNG1 has indicated that EGFR-TKI rechallenge does not contribute to OS [24]. On the other hand, there are reports on the utility of EGFR-TKI rechallenge, particularly rechallenge after previous gefitinib treatment. In cases where the therapeutic effect of EGFR-TKI treatment was helpful, rechallenge can be an option when there is no other treatment choice [25-29].

Currently, standard second-line and subsequent treatments have not been established, especially for elderly patients with advanced NSCLC. Therefore, the effectiveness of rechallenge treatment in elderly patients with advanced NSCLC harboring EGFR mutations remains unclear. There are several treatment choices for elderly patients with advanced NSCLC. They are BSCs and third-generation drug monotherapy or non-platinum based or platinum-based combination chemotherapy, EGFR-TKI. However, the selection of treatment for elderly patients is limited by the performance status. 
Previously, Inoue et al. reported that $37 \%$ of non-elderly patients with EGFR-mutated NSCLC received second- or subsequent EGFR-TKI rechallenge after first-line gefitinib [30]. In this study, because the subjects were elderly, only $22(28 \%)$ of the 78 patients received EGFR-TKI rechallenge treatment after failure of first-line EGFR-TKI treatment. However, there are limited studies on elder NSCLC patients harboring EGFR mutations after subsequent treatment. In a study by Kuwako et al. [15], only 8 (13\%) of the 62 patients who relapsed subsequently received EGFR-TKI rechallenge. Moreover, 11 patients received second-line chemotherapy (18\%), which was more than those who received EGFR-TKI rechallenge treatment. Most $(42 / 62 ; 68 \%)$ chose treatment with the best supportive care available. In our cohort, more than $50 \%$ of patients received second-line treatment and as many as $10(13 \%)$ received third-line treatment. Among these, the number of cases of EGFR-TKI re-challenge was $22(28 \%)$, which was higher than that of Kuwako's study. Low-dose treatment of erlotinib has been reported to be both safe and effective, especially in elderly and frail patients [31].

In elderly patients, due to the presence of age-related organ dysfunctions and potentially complex complications, there is low resistance to chemotherapy toxicity as compared to younger patients. Therefore, the choice of cytotoxic chemotherapy is often withheld.

In clinical practice, the proportion of second-line cytotoxic chemotherapy for elderly patients with EGFR mutated NSCLC might be less likely than for adult patients.

Monotherapy of cytotoxic drug is currently standard first-line treatment for elderly patients with NSCLC. Kudo et al. reported cytotoxic drug monotherapy for elderly patients with advanced NSCLC in Japan. In this study, vinorelbine or docetaxel are selected for monotherapy, RR is 10 to $23 \%$, PFS is 3.1 to 5.5 months, and OS is 9.9 to 14.0 months, respectively [32]. Although the number of patients in our study was smaller than in previous studies, our results were equivalent to the outcome of first-line treatment for elderly patients with metastatic NSCLC.

Most patients with NSCLC eventually become refractory to treatment, despite a good response to first-line treatment for EGFR-TKIs. Most treatment resistance is due to acquired EGFR mutations (i.e., T790M) or amplification of the MET oncogene [33].

Osimertinib, a third-generation EGFR-TKI, shows a better safety profile with monotherapy and is particularly useful for EGFR-TKI-resistant NSCLC with T790M mutations [34]. However, it is necessary to detect T790M by re-biopsy after using EGFR-TKI prior to administration of Osimertinib. For this reason, re-biopsy is important for deciding the next treatment. Unfortunately, in this study, most patients died before the T790M was evaluated, and the status of the T790M in most patients was unclear. Currently, T790M can be detected by repeating liquid biopsy instead of tissue re-biopsy. The expression rate of T790M due to repetition of tissue re-biopsy and liquid biopsy is different depending on the report [35-40]. However, the expression frequency of T790M in the re-biopsy of elderly patients is unclear.

Moreover, EGFR-TKIs should be able to switch to another treatment, or decide whether it should continue at the time of treatment failures. Continuation of gefitinib after radiological disease progression on first-line gefitinib did not prolong PFS in patients who received platinum-based doublet chemotherapy as subsequent line of treatment [41].

As mentioned above, elderly patients have many comorbidities and organ dysfunction as compared to young patients.

Thus, the toxicity associated with the treatment of elderly patients is an important issue. However, adverse events of EGFR-TKI rechallenge of elderly patients in this study were mild and predictable and their incidence and severity adverse events were similar to those observed in patients who received first-line treatment [32,42,43]. Moreover, few grade 3 events were observed and no treatment-related deaths were observed. Regardless of the severity, adverse hematological and non-hematological events were controllable.

Consequently, $82 \%$ of patients in this study were administered erlotinib after initial gefitinib treatment. The second-generation EGFR-TKI, erlotinib, was used in all cases in this study. In contrast, only three out of 22 patients received afatinib. 
This is probably because the study period was from 2008 to 2015, and afatinib only became available in Japan in 2014.

In a Japanese study, Tamiya et al. reported that PFS was prolonged compared to the osimertinib-administered group after afatinib administration, as well as the osimertinibadministered group after gefitinib/erlotinib administration [44].

However, T790M mutation must be positive to allow osimertinib to be used after afatinib, and it has not been determined as the treatment method of T790M-negative cases after re-biopsy.

There is some prior research on EGFR-TKI and BSA or dose change, many of which are Japanese reports, and are limited to the studies of gefitinib or afatinib [45,46]. The cutoff value of the BSA in the previous report was $1.45-1.57 \mathrm{~m}^{2}$. In this study, $1.4 \mathrm{~m}^{2}$ became the cut-off value because the subject patients tended to be physically small. Furthermore, PFS or OS was prolonged when BSA was small as in the prior study, but there is no report that suggests the relationship with BSA for rechallenge, as in this study. Moreover, in this study, most of the agents that had a dose change for erlotinib, and the dose reduction in the elderly of smaller physique is considered to contribute to toxic control and treatment continuity. In other words, dose reduction may contribute to the continuation of treatment in elderly Japanese with deterioration of organ function and a smaller BSA.

In recent years, treatment methods for each EGFR mutation have been proposed, and especially for the exon21 L858R mutation, and due to the therapeutic effects of erlotinib and ramucirumab combination treatment, erlotinib has been attracting attention again [47]. Ramucirumab, a vascular endothelial growth factor (VGEF) inhibitor, has been used in combination with the treatment in this study. However, because it is generally difficult to administer to the elderly, erlotinib and ramucirumab combination treatment is not a treatment option for them.

Although it is in the clinical trial stage, third-generation EGFR-TKIs, nazartinib (EGF816) [48], lazertinib (YH25448) [49], abivertinib (AC0010) [50], and almonertinib (HS 10296) [51] are currently undergoing trials as first-line treatments. However, up to the present, the results for osimertinib and the extent of effectiveness have not been obtained.

There are several limitations to this study. First, this is a retrospective study for the selected patients. Second, EGFR-TKI selection is determined by the attending physician, and there might be selection bias in these decisions. Moreover, as a result, the choice can affect the survival after second-line treatment. The final limitation is a comparatively small population, which could not show statistical significance. To verify our findings for validity in clinical practice, there is a need for a larger prospective study.

\section{Conclusions}

In conclusion, our results indicate that EGFR-TKI rechallenge after first-line EGFRTKI treatment in elderly patients with advanced NSCLC harboring drug-sensitive EGFR mutations was effective and tolerable. Approximately $28 \%$ of the elderly patients received EGFR-TKI rechallenge after first-line EGFR-TKI treatment. Despite the retrospective design, our findings show that EGFR-TKI rechallenge should be considered as a standard treatment after failure of EGFR-TKI in elderly patients with advanced NSCLC with T790M-negative EGFR mutations. Lastly, for elderly Japanese with a smaller BSA, dose reduction of EGFRTKI might be a useful factor for continuation of treatment.

Author Contributions: Y.Y. and H.I. wrote the first draft of the manuscript; Y.Y. performed the statistical analysis. Y.Y., H.I., T.S., H.M., K.K. (Kenya Kanazawa), T.K. (Takashi Kasai), K.M., K.K. (Kyoichi Kaira), and T.K. (Takayuki Kaburagi) reviewed and edited the manuscript, made substantial contributions to the design of the work, and approved the final version of the manuscript. All authors have read and agreed to the published version of the manuscript.

Funding: This research received no specific grant from any funding agency in the public, commercial, or not-for-profit sectors. 
Institutional Review Board Statement: The study was conducted according to the guidelines of the Declaration of Helsinki, and approved by the institutional review board of each institution.

Informed Consent Statement: The need for informed consent was waived by the Institutional Review Boards of each participating institution because of the retrospective nature of the study.

Data Availability Statement: The data are not publicly available due to localization in the hospital.

Acknowledgments: We thank Toru Yamada and Naomi Yamada.

Conflicts of Interest: No Authors have any conflict of interest to disclose regarding this study.

\section{References}

1. Miller, K.D.; Siegel, R.L.; Lin, C.C.; Mariotto, A.B.; Kramer, J.L.; Rowland, J.H.; Jemal, A. Cancer treatment and survivorship statistics, 2016. CA Cancer J. Clin. 2016, 66, 271-289. [CrossRef]

2. Davidoff, A.J.; Tang, M.; Seal, B.; Edelman, M.J. Chemotherapy and survival benefit in elderly patients with advanced non-small cell lung cancer. J. Clin. Oncol. 2010, 28, 2191-2197. [CrossRef]

3. Owonikoko, T.K.; Ragin, C.C.; Belani, C.P.; Oton, A.B.; Gooding, W.E.; Taioli, E.; Ramalingam, S.S. Lung cancer in elderly patients: An analysis of the surveillance, epidemiology, and end results database. J. Clin. Oncol. 2007, 25, 5570-5577. [CrossRef] [PubMed]

4. Mok, T.S.; Wu, Y.L.; Thongprasert, S.; Yang, C.H.; Chu, D.T.; Saijo, N.; Fukuoka, M. Gefitinib or carboplatin-paclitaxel in pulmonary adenocarcinoma. N. Engl. J. Med. 2009, 361, 947-957. [CrossRef] [PubMed]

5. Maemondo, M.; Inoue, A.; Kobayashi, K.; Sugawara, S.; Oizumi, S.; Isobe, H.; Nukiwa, T. Gefitinib or chemotherapy for non-small-cell lung cancer with mutated EGFR. N. Engl. J. Med. 2010, 362, 2380-2388. [CrossRef] [PubMed]

6. Mitsudomi, T.; Morita, S.; Yatabe, Y.; Negoro, S.; Okamoto, I.; Tsurutani, J. West Japan Oncology Group. Gefitinib versus cisplatin plus docetaxel in patients with non-small-cell lung cancer harbouring mutations of the epidermal growth factor receptor (WJTOG3405): An open label, randomised phase 3 trial. Lancet Oncol. 2010, 11, 121-128. [CrossRef]

7. Rosell, R.; Carcereny, E.; Gervais, R.; Vergnenegre, A.; Massuti, B.; Felip, E.; Paz-Ares, L. Erlotinib versus standard chemotherapy as first-line treatment for European patients with advanced EGFR mutation-positive non-small-cell lung cancer (EURTAC): A multicentre, open-label, randomized phase 3 trial. Lancet Oncol. 2012, 13, 239-246. [CrossRef]

8. Zhou, C.; Wu, Y.-L.; Chen, G.; Feng, J.; Liu, X.-Q.; Wang, C.; Zhang, S.; Wang, J.; Zhou, S.; Ren, S.; et al. Final overall survival results from a randomised, phase III study of erlotinib versus chemotherapy as first-line treatment of EGFR mutation-positive advanced non-small-cell lung cancer (OPTIMAL, CTONG-0802). Ann. Oncol. 2015, 26, 1877-1883. [CrossRef]

9. Yang, J.C.H.; Wu, Y.L.; Schuler, M.; Sebastian, M.; Popat, S.; Yamamoto, N.; Sequist, L.V. Afatinib versus cisplatin-based chemotherapy for EGFR mutation-positive lung ad-enocarcinoma (LUX-Lung 3 and LUX-Lung 6): Analysis of overall survival data from two randomised, phase 3 trials. Lancet Oncol. 2015, 16, 141-151. [CrossRef]

10. Maemondo, M.; Minegishi, Y.; Inoue, A.; Kobayashi, K.; Harada, M.; Okinaga, S.; Gemmah, A. First-line gefitinib in patients aged 75 or older with advanced non-small cell lung cancer harboring epidermal growth factor receptor mutations: NEJ 003 study. J. Thorac. Oncol. 2012, 7, 1417-1422. [CrossRef] [PubMed]

11. Fujita, S.; Katakami, N.; Masago, K.; Yoshioka, H.; Tomii, K.; Kaneda, T.; Mio, T. Customized chemotherapy based on epidermal growth factor receptor mutation status for elderly patients with advanced non-small-cell lung cancer: A phase II trial. BMC Cancer 2012, 12, 185. [CrossRef]

12. Tateishi, K.; Ichiyama, T.; Hirai, K.; Agatsuma, T.; Koyama, S.; Hachiya, T.; Koizumi, T. Clinical outcomes in elderly patients administered gefitinib as first-line treatment in epidermal growth factor receptor-mutated non-small-cell lung cancer: Retrospective analysis in a Nagano Lung Cancer Research Group study. Med. Oncol. 2013, 30, 450. [CrossRef]

13. Goto, K.; Nishio, M.; Yamamoto, N.; Chikamori, K.; Hida, T.; Maemondo, M.; Katakami, N.; Kozuki, T.; Yoshioka, H.; Seto, T.; et al. A prospective, phase II, open-label study (JO22903) of first-line erlotinib in Japanese patients with epidermal growth factor receptor (EGFR) mutation-positive advanced non-small-cell lung cancer (NSCLC). Lung Cancer 2013, 82, 109-114. [CrossRef]

14. Takahashi, K.; Saito, H.; Hasegawa, Y.; Ando, M.; Yamamoto, M.; Kojima, E.; Suzuki, R. First-line gefitinib therapy for elderly patients with non-small cell lung cancer harboring EGFR mutation: Central Japan Lung Study Group 0901. Cancer Chemother. Pharm. 2014, 74, 721-727. [CrossRef]

15. Kuwako, T.; Imai, H.; Masuda, T.; Miura, Y.; Seki, K.; Yoshino, R.; Yamada, M. First-line gefitinib treatment in elderly patients (aged $>$ /=75 years) with non-small cell lung cancer harboring EGFR mutations. Cancer Chemother. Pharmacol. 2015, 76, 761-769. [CrossRef] [PubMed]

16. Wu, Y.-L.; Zhou, C.; Hu, C.-P.; Feng, J.; Lu, S.; Huang, Y.; Li, W.; Hou, M.; Shi, J.H.; Lee, K.Y.; et al. Afatinib versus cisplatin plus gemcitabine for first-line treatment of Asian patients with advanced non-small-cell lung cancer harbouring EGFR mutations (LUX-Lung 6): An open-label, randomised phase 3 trial. Lancet Oncol. 2014, 15, 213-222. [CrossRef]

17. Sequist, L.V.; Yang, J.C.-H.; Yamamoto, N.; Obyrne, K.J.; Hirsh, V.; Mok, T.; Geater, S.L.; Orlov, S.; Tsai, C.-M.; Boyer, M.; et al. Phase III Study of Afatinib or Cisplatin Plus Pemetrexed in Patients with Metastatic Lung Adenocarcinoma with EGFR Mutations. J. Clin. Oncol. 2013, 31, 3327-3334. [CrossRef] [PubMed] 
18. Tomizawa, Y.; Fujita, Y.; Tamura, A.; Shirai, M.; Shibata, S.; Kawabata, T.; Shibayama, T.; Fukai, S.; Kawahra, M.; Saito, R. Effect of gefitinib re-challenge to initial gefitinib responder with non-small cell lung cancer followed by chemotherapy. Lung Cancer 2010, 68, 269-272. [CrossRef]

19. Imai, H.; Gunma-Ibaraki-Fukushima-Tochigi (GIFT) Group; Minemura, H.; Sugiyama, T.; Yamada, Y.; Kaira, K.; Kanazawa, K.; Kasai, T.; Kaburagi, T.; Minato, K. Efficacy and safety of cytotoxic drug chemotherapy after first-line EGFR-TKI treatment in elderly patients with non-small-cell lung cancer harboring sensitive EGFR mutations. Cancer Chemother. Pharmacol. 2018, 82, 119-127. [CrossRef]

20. Goldstraw, P.; Crowley, J.; Chansky, K.; Giroux, D.J.; Groome, P.A.; Rami-Porta, R. International Association for the Study of Lung Cancer International Staging Committee. The IASLC Lung Cancer Staging Project: Proposals for the revision of the TNM stage groupings in the forthcoming (seventh) edition of the TNM Classification of malignant tumours. J. Thorac. Oncol. 2007, 2, 706-714.

21. Nagai, Y.; Miyazawa, H.; Tanaka, T.; Udagawa, K.; Kato, M.; Fukuyama, S.; Hagiwara, K. Genetic heterogeneity of the epidermal growth factor receptor in non-small cell lung cancer cell lines revealed by a rapid and sensitive detection system, the peptide nucleic acid-locked nucleic acid PCR clamp. Cancer Res. 2005, 65, 7276-7282. [CrossRef]

22. Yatabe, Y.; Hida, T.; Horio, Y.; Kosaka, T.; Takahashi, T.; Mitsudomi, T. A Rapid, Sensitive Assay to Detect EGFR Mutation in Small Biopsy Specimens from Lung Cancer. J. Mol. Diagn. 2006, 8, 335-341. [CrossRef]

23. Eisenhauer, E.A.; Therasse, P.; Bogaerts, J.; Schwartz, L.H.; Sargent, D.; Ford, R.; Verweij, J. New response evaluation criteria in solid tumours: Revised RECIST guideline (version 1.1). Eur. J. Cancer 2009, 45, 228-247. [CrossRef]

24. Miller, V.A.; Hirsh, V.; Cadranel, J.; Chen, Y.-M.; Park, K.; Kim, S.-W.; Zhou, C.; Su, W.-C.; Wang, M.; Sun, Y.; et al. Afatinib versus placebo for patients with advanced, metastatic non-small-cell lung cancer after failure of erlotinib, gefitinib, or both, and one or two lines of chemotherapy (LUX-Lung 1): A phase 2b/3 randomised trial. Lancet Oncol. 2012, 13, 528-538. [CrossRef]

25. Chang, G.-C.; Tseng, C.-H.; Hsu, K.-H.; Yu, C.-J.; Yang, C.-T.; Chen, K.-C.; Yang, T.-Y.; Tseng, J.-S.; Liu, C.-Y.; Liao, W.-Y.; et al. Predictive factors for EGFR -tyrosine kinase inhibitor retreatment in patients with EGFR -mutated non-small-cell lung cancer - A multicenter retrospective SEQUENCE study. Lung Cancer 2017, 104, 58-64. [CrossRef] [PubMed]

26. Chen, Y.-M.; Lai, C.-H.; Rau, K.-M.; Huang, C.-H.; Chang, H.-C.; Chao, T.-Y.; Tseng, C.-C.; Fang, W.-F.; Chung, Y.-H.; Wang, Y.-H.; et al. Impact of clinical parameters and systemic inflammatory status on epidermal growth factor receptor-mutant non-small cell lung cancer patients readministration with epidermal growth factor receptor tyrosine kinase inhibitors. $B M C$ Cancer 2016, 16, 1-7. [CrossRef] [PubMed]

27. Kuiper, J.L.; Heideman, D.A.; Würdinger, T.; Grünberg, K.; Groen, H.J.; Smit, E.F. Rationale and Study Design of the IRENE-Trial (NVALT-16): A Phase II Trial to Evaluate Iressa Rechallenge in Advanced NSCLC Patients With an Activating EGFR Mutation Who Responded to an EGFR-TKI Used As First-Line or Previous Treatment. Clin. Lung Cancer 2015, 16, 60-66. [CrossRef]

28. Xia, G.-H.; Zeng, Y.; Fang, Y.; Yu, S.-R.; Wang, L.; Shi, M.-Q.; Sun, W.-L.; Huang, X.-E.; Chen, J.; Feng, J.-F. Effect of EGFR-TKI retreatment following chemotherapy for advanced non-small cell lung cancer patients who underwent EGFR-TKI. Cancer Biol. Med. 2014, 11, 270-276. [CrossRef] [PubMed]

29. Song, Z.; Yu, X.; He, C.; Zhang, B.; Zhang, Y. Re-administration after the failure of gefitinib or erlotinib in patients with advanced non-small cell lung cancer. J. Thorac. Dis. 2013, 5, 400-405. [CrossRef] [PubMed]

30. Inoue, A.; Kobayashi, K.; Maemondo, M.; Sugawara, S.; Oizumi, S.; Isobe, H.; North-East Japan Study Group. Updated overall survival results from a randomized phase III trial comparing gefitinib with carboplatin-paclitaxel for chemo-naive non-small cell lung cancer with sensitive EGFR gene mutations (NEJ002). Ann. Oncol. 2013, 24, 54-59. [CrossRef] [PubMed]

31. Miyamoto, S.; Azuma, K.; Ishii, H.; Bessho, A.; Hosokawa, S.; Fukamatsu, N.; Okamoto, H. Low-Dose Erlotinib Treatment in Elderly or Frail Patients With EGFR Mutation-Positive Non-Small Cell Lung Cancer A Multicenter Phase 2 Trial. JAMA Oncol. 2020, 6, e201250. [CrossRef] [PubMed]

32. Kudoh, S.; Takeda, K.; Nakagawa, K.; Takada, M.; Katakami, N.; Matsui, K.; Fukuoka, M. Phase III study of docetaxel compared with vinorelbine in elderly patients with advanced non-small-cell lung cancer: Results of the West Japan Thoracic Oncology Group Trial (WJTOG 9904). J. Clin. Oncol. 2006, 24, 3657-3663. [CrossRef] [PubMed]

33. Takeuchi, S.; Yano, S. Clinical significance of epidermal growth factor receptor tyrosine kinase inhibitors: Sensitivity and resistance. Respir. Investig. 2014, 52, 348-356. [CrossRef] [PubMed]

34. Mok, T.S.; Wu, Y.L.; Ahn, M.J.; Garassino, M.C.; Kim, H.R.; Ramalingam, S.S.; Papadimitrakopoulou, V.A. Osimertinib or platinumpemetrexed in EGFR T790M-positive lung cancer. N. Engl. J. Med. 2017, 376, 629-640. [CrossRef] [PubMed]

35. Ko, R.; Kenmotsu, H.; Serizawa, M.; Koh, Y.; Wakuda, K.; Ono, A.; Takahashi, T. Frequency of EGFR T790M mutation and multimutational profiles of rebiopsy samples from non-small cell lung cancer developing acquired resistance to EGFR tyrosine kinase inhibitors in Japanese patients. BMC Cancer 2016, 16, 864. [CrossRef] [PubMed]

36. Pereira, I.; Gaspar, C.; Pina, M.; Azevedo, I.; Rodrigues, A. Real-World T790M Mutation Frequency and Impact of Rebiopsy in Patients With EGFR-Mutated Advanced Non-Small Cell Lung Cancer. Cureus 2020, 12. [CrossRef]

37. Nam, Y.; Kim, H.C.; Kim, Y.; Jang, S.H.; Lee, K.Y.; Lee, S.Y.; Lee, S.H.; Lee, S.Y.; Yoon, S.H.; Ryu, J.; et al. Clinical impact of rebiopsy among patients with epidermal growth factor receptor-mutant lung adenocarcinoma in a real-world clinical setting. Thorac. Cancer 2021, 12, 890-898. [CrossRef]

38. Ninomaru, T.; Hata, A.; Kokan, C.; Okada, H.; Tomimatsu, H.; Ishida, J. Higher osimertinib introduction rate achieved by multiple repeated rebiopsy after acquired resistance to first/second generation EGFR-TKIs. Thorac. Cancer 2021, 12, 746-751. [CrossRef] 
39. Mountzios, G.; Koumarianou, A.; Bokas, A.; Mavroudis, D.; Samantas, E.; Fergadis, E.; Linardou, H.; Katsaounis, P.; Athanasiadis, E.; Karamouzis, M.; et al. A Real-World, Observational, Prospective Study to Assess the Molecular Epidemiology of Epidermal Growth Factor Receptor (EGFR) Mutations upon Progression on or after First-Line Therapy with a First- or Second-Generation EGFR Tyrosine Kinase Inhibitor in EGFR Mutation-Positive Locally Advanced or Metastatic Non-Small Cell Lung Cancer: The 'LUNGFUL' Study. Cancers 2021, 13, 3172. [CrossRef]

40. Zhang, Y.; Xiong, L.; Xie, F.; Zheng, X.; Li, Y.; Zhu, L.; Sun, J. Next-generation sequencing of tissue and circulating tumor DNA: Resistance mechanisms to EGFR targeted therapy in a cohort of patients with advanced non-small cell lung cancer. Cancer Med. 2021, 10, 4697-4709. [CrossRef]

41. Soria, J.C.; Wu, Y.L.; Nakagawa, K.; Kim, S.W.; Yang, J.J.; Ahn, M.J.; Mok, T.S. Gefitinib plus chemotherapy versus placebo plus chemotherapy in EGFR-mutationpositive non-small-cell lung cancer after progression on first-line gefitinib (IMPRESS): A phase 3 randomised trial. Lancet Oncol. 2015, 16, 990-998. [CrossRef]

42. Abe, T.; Takeda, K.; Ohe, Y.; Kudoh, S.; Ichinose, Y.; Okamoto, H.; Tamura, T. Randomized phase III trial comparing weekly docetaxel plus cisplatin versus docetaxel monotherapy every 3 weeks in elderly patients with advanced non-small-cell lung cancer: The intergroup trial JCOG0803/WJOG4307L. J. Clin. Oncol. 2015, 33, 575-581. [CrossRef] [PubMed]

43. Quoix, E.; Zalcman, G.; Oster, J.P.; Westeel, V.; Pichon, E.; Lavolé, A. Carboplatinand weekly paclitaxel doublet chemotherapy compared with mono-therapy in elderly patients with advanced non-small-cell lung cancer: IFCT- 0501 randomised, phase 3 trial. Lancet 2011, 378, 1079-1088. [CrossRef]

44. Tamiya, M.; Tamiya, A.; Suzuki, H.; Moriizumi, K.; Nakahama, K.; Taniguchi, Y.; Kunimasa, K.; Kimura, M.; Inoue, T.; Kuhara, H.; et al. Which Is Better EGFR-TKI Followed by Osimertinib: Afatinib or Gefitinib/Erlotinib? Anticancer Res. 2019, 39, 3923-3929. [CrossRef]

45. Hirano, R.; Uchino, J.; Ueno, M.; Fujita, M.; Watanabe, K. Low-dose Epidermal Growth Factor Receptor (EGFR)-Tyrosine Kinase Inhibition of EGFR Mutation-positive Lung Cancer: Therapeutic Benefits and Associations Between Dosage, Efficacy and Body Surface Area. Asian Pac. J. Cancer Prev. 2016, 17, 785-789. [CrossRef]

46. Sonehara, K.; Kobayashi, T.; Tateishi, K.; Morozumi, N.; Yoshiike, F.; Hachiya, T.; Ono, Y.; Takasuna, K.; Agatsuma, T.; Masubuchi, T.; et al. Clinical analysis ofEGFR-positive non-small cell lung cancer patients treated with first-line afatinib: A Nagano Lung Cancer Research Group. Thorac. Cancer 2019, 10, 1078-1085. [CrossRef]

47. Nakagawa, K.; Garon, E.B.; Seto, T.; Nishio, M.; Aix, S.P.; Paz-Ares, L.; Dakhil, S. Ramucirumab plus erlotinib in patients with untreated, EGFR-mutated, advanced non-small-cell lung cancer (RELAY): A randomised, double-blind, placebo-controlled, phase 3 trial. Lancet Oncol. 2019, 20, 1655-1669. [CrossRef]

48. Tan, D.S.-W.; Leighl, N.B.; Riely, G.J.; Yang, J.C.-H.; Sequist, L.V.; Wolf, J.; Seto, T.; Felip, E.; Aix, S.P.; Jonnaert, M.; et al. Safety and efficacy of nazartinib (EGF816) in adults with EGFR-mutant non-small-cell lung carcinoma: A multicentre, open-label, phase 1 study. Lancet Respir. Med. 2020, 8, 561-572. [CrossRef]

49. Ahn, M.J.; Han, J.Y.; Lee, K.H.; Kim, S.W.; Kim, D.W.; Lee, Y.G.; Cho, B.C. Lazertinib in patients with EGFR mutation-positive advanced non-small-cell lung cancer: Results from the dose escalation and dose expansion parts of a first-in-human, open-label, multicentre, phase 1-2 study. Lancet Oncol. 2019, 20, 1681-1690. [CrossRef]

50. Wang, H.; Pan, R.; Zhang, X.; Si, X.; Wang, M.; Zhang, L. Abivertinib in patients with T790M-positive advanced NSCLC and its subsequent treatment with osimertinib. Thorac. Cancer 2020, 11, 594-602. [CrossRef]

51. Yang, J.C.-H.; Camidge, D.R.; Yang, C.-T.; Zhou, J.; Guo, R.; Chiu, C.-H.; Chang, G.-C.; Shiah, H.-S.; Chen, Y.; Wang, C.-C.; et al. Safety, Efficacy, and Pharmacokinetics of Almonertinib (HS-10296) in Pretreated Patients With EGFR-Mutated Advanced NSCLC: A Multicenter, Open-label, Phase 1 Trial. J. Thorac. Oncol. 2020, 15, 1907-1918. [CrossRef] [PubMed] 